\title{
Interactive comment on "The Depth Limit for the Formation and Occurrence of Fossil Fuel Resources” by Xiongqi Pang et al.
}

\section{Xiongqi Pang et al.}

pangxq@cup.edu.cn

Received and published: 8 November 2019

We are grateful for the suggestions provided by the scientific community and for the time to review this manuscript. Our responses to these comments are attached to the supplement.

Please also note the supplement to this comment: https://www.earth-syst-sci-data-discuss.net/essd-2019-72/essd-2019-72-AC1supplement.pdf 2019. 